\section{Myocardial calcium-independent nitric oxide synthase activity is present in dilated cardiomyopathy, myocarditis, and postpartum cardiomyopathy but not in ischaemic or valvar heart disease}

Adam J de Belder, Marek W Radomski, Howard J Why, Peter J Richardson,
John F Martin

Adam J de Belder, Marek W Radomski, Howard J Why, Peter J Richardson,
John F Martin Abstract

Objective-To determine the activity of the calcium-dependent constitutive (cNOS) and calcium-independent inducible nitric oxide (iNOS) synthases in heart tissue from patients with different cardiac diseases.

Patients and design-Endomyocardial biopsy specimens were obtained from patients with dilated hearts (by echocardiography and ventriculography) and normal coronary arteries (by selective angiography). Recognised clinical, radiological, and histopathological criteria were used to diagnose non-inflammatory dilated cardiomyopathy (DCM) $(n=6)$, inflammatory cardiomyopathy (ICM) $(n=5)$, and peripartum cardiomyopathy (PPCM) (n= 3). Comparative groups were chosen with similarly dilated hearts caused by ischaemic $(n=5)$ or valvar disease $(n=4)$, and, in addition, nondilated hearts with ischaemic $(n=5)$ and valvar $(n=3)$ disease. Venous blood was taken at the time of myocardial biopsy for assay of plasma tumour necrosis factor alpha (TNFa).

Results-Myocardial tissue from patients with DCM, ICM, and PPCM showed considerable iNOS activity $(16 \cdot 8(2 \cdot 7)$ pmol citrulline/mg protein/min) with little or no cNOS activity $(1.3(0.9)$ pmol citrulline/mg protein/min). In contrast, myocardial tissue from patients with both dilated and non-dilated hearts of ischaemic or valvar aetiology showed cNOS and little, if any, iNOS activity (dilated-cNOS $11.7(2.4)$ and iNOS 0.8 (0.6) $\mathrm{pmol}$ citrulline/mg protein/min; non-dilated-cNOS $12.1(1.8)$ and iNOS $1.4(0.8) \mathrm{pmol}$ citrulline $/ \mathrm{mg}$ protein/ min). Plasma TNFa was detectable only in patients with inflammatory $D C M$.

Conclusions-These results support the hypothesis the generation of nitric oxide by iNOS accounts for some of the dilatation and impaired contractility associated with inflammatory and noninflammatory dilated cardiomyopathy and peripartum cardiomyopathy.
(Br Heart $\mathcal{F} 1995 ; 74: 426-430)$

Keywords: nitric oxide; cardiomyopathy

The clinical management of patients with dilated heart muscle disease is limited to treating the consequences, rather than the causes, of the myocardial damage because the cellular and immune mechanisms underlying the pathology are poorly understood. Recent research has suggested that the myocardial generation of nitric oxide (NO) may be important in the negative inotropism associated with these conditions. ${ }^{1}$

Nitric oxide is generated from L-arginine by the NO synthases. ${ }^{2}$ One is constitutive (cNOS), $\mathrm{Ca}^{2+} /$ calmodulin and NADPH dependent, and generates NO from the endothelium. Under basal conditions the endothelial generation of NO maintains vascular tone by stimulating the soluble guanylate cyclase, thus increasing cyclic GMP in smooth muscle cells. ${ }^{3}$ The cNOS has been demonstrated in the endocardial endothelium $^{4}$ and cardiac myocytes. ${ }^{1}$ Nitric oxide is known to have negative chronotropic ${ }^{5}$ and inotropic effects ${ }^{6-8}$ in several in vitro cardiac preparations.

A further enzyme that generates NO requires appropriate cytokines for its de novo gene transcription. This so-called inducible NO synthase (iNOS) has been purified and cloned in human cells, ${ }^{910}$ and generates large quantities of NO. The systemic generation of NO by this enzyme in the vasculature accounts for the profound decrease in peripheral tone and the resistance to vasoconstrictors that occurs in endotoxaemia. ${ }^{1112}$ Inhibitors of NO synthesis have proved to be beneficial in patients with septic shock. ${ }^{13}$ However, it is apparent that under certain inflammatory conditions in various tissues, local NO generation by the iNOS has important physiological and pathophysiological effects. ${ }^{14}$ Indeed, cultured endocardial cells ${ }^{15}$ and myocytes ${ }^{16}$ express the iNOS after endotoxaemic and cytokine challenge, and NO generated by this pathway has profound negative inotropic effects in several animal myocardial preparations. ${ }^{16-18}$ Thus the 
impaired cardiac function seen with different inflammatory heart muscle disorders, such as endotoxaemia, acute myocarditis, heart transplant rejection, postpartum cardiomyopathy, interleukin-induced cardiomyopathy, and dilated cardiomyopathy (DCM) may be due to increased NO generation by this enzyme. ${ }^{1}$ In support of this hypothesis, we showed the presence of the iNOS in ventricular tissue from patients with DCM. ${ }^{19}$ To determine whether this enzyme is present in other heart conditions, we determined the NO synthase activities in ventricular tissue obtained from non-dilated hearts (ischaemic heart disease and aortic stenosis) and dilated hearts (noninflammatory and inflammatory dilated cardiomyopathy, peripartum cardiomyopathy, aortic regurgitation, and ischaemic cardiomyopathy).

\section{Patients and methods}

This investigation was approved by the King's College Hospital ethics committee. All patients gave informed consent for this investigation.

\section{PATIENTS}

All patients underwent transthoracic echocardiography, using a Hewlett Packard 1500 Sonos system with a $2.5 \mathrm{MHz}$ phased array transducer. Left ventricular dimensions were measured from the left parasternal edge in the long axis.

\section{DILATED HEARTS}

Non-inflammatory dilated cardiomyopathy was diagnosed in six patients with clinical evidence of heart failure, dilated hearts on echocardiography, normal coronary arteries on selective angiography, and the absence of specific heart muscle disorder on histological examination of an endomyocardial biopsy specimen.

Inflammatory dilated cardiomyopathy was diagnosed in five patients in heart failure with dilated hearts and normal coronary arteries. Endomyocardial biopsy specimens from patients in this group were not examined by specific immunohistochemical staining. A cardiac pathologist made the distinction between inflammatory and non-inflammatory disease based on histological examination for areas of lymphocytic infiltration, interstitial widening with an increase in interstitial fibrous tissue, and little or no necrosis.

Peripartum cardiomyopathy was defined as heart failure that developed in the last month of pregnancy or within the first five postpartum months for which there was no other determinable cause or cardiac disease. ${ }^{20}$ The three patients in this group developed severe cardiac failure, one month, two months, and five months after delivery. Right ventricular endomyocardial biopsy specimens were obtained at cardiac catheterisation.

Ischaemic dilated cardiomyopathy $(n=5)$ was defined as heart failure in the presence of a dilated myocardium with occlusive coronary artery disease sufficient to account for the impaired cardiac dysfunction. Endomyocardial biopsy specimens of the right ventricle were taken at the time of cardiac catheterisation. Aortic regurgitation $(n=4)$ was defined as heart failure caused by grade III/IV aortic valve regurgitation (as defined by echocardiography and ventriculography) in the presence of normal coronary arteries. Right ventricular Trucut biopsy specimens were obtained at the time of valve replacement.

\section{NON-DILATED HEARTS}

Aortic stenosis $(n=3)$ was defined as symptoms of chest pain or syncope with a calcified aortic valve with echocardiographic and catheter evidence of a gradient of $>80 \mathrm{~mm} \mathrm{Hg}$ across the valve and normal coronary arteries. Right ventricular Trucut biopsy specimens were obtained at the time of valve replacement.

Non-dilated ischaemic hearts $(n=5)$.- Right ventricular Trucut biopsies were obtained from patients undergoing coronary bypass surgery who had normal ventricular function on echocardiography and ventriculography.

\section{BIOCHEMISTRY}

All myocardial tissue was snap frozen in liquid nitrogen at biopsy and stored at $-70^{\circ} \mathrm{C}$. Tissue was freeze-crushed and homogenised in ice cold buffer, then centrifuged at $20000 \mathrm{~g}$ for $20 \mathrm{~min}$. The soluble fraction was used to measure the constitutive and inducible (in the presence of $1 \mathrm{mmol}$ ethylene glycol tetraacetic acid) activity of NO synthase, by using the conversion of ${ }^{14} \mathrm{C}$-L-arginine to ${ }^{14} \mathrm{C}-\mathrm{L}$ citrulline, as previously described (detection limit $<0 \cdot 1 \mathrm{pmol}$ citrulline $/ \mathrm{mg}$ protein $/ \mathrm{min}) .{ }^{21}$

\section{CYTOKINE MEASUREMENTS}

Venous blood was collected at the time of cardiac catheterisation from the antecubital fossa. Plasma was stored at $-20^{\circ} \mathrm{C}$ until immunoassay (Amersham, UK) for tumour necrosis factor (TNFa).

\section{STATISTICAL ANALYSIS}

Results are presented as means (SEM), and results are compared by analysis of variance (ANOVA). $P<0.05$ is regarded as statistically significant.

\section{Results}

ECHOCARDIOGRAPHIC AND

VENTRICULOGRAPHIC DATA

Patients were selected for the study if they fitted the diagnostic criteria above. The table shows the echocardiographic and ventriculographic data on the cardiac dimensions for the different groups. There were no significant differences in left ventricular dimensions between the groups with dilated hearts.

\section{NITRIC OXIDE SYNTHASE ASSAY}

Patients with dilated cardiomyopathy (inflammatory and non-inflammatory) and peripartum cardiomyopathy expressed iNOS $(16 \cdot 8(2 \cdot 7) \mathrm{pmol}$ citrulline $/ \mathrm{mg} /$ protein $/ \mathrm{min})$ with little or no cNOS activity $(1.3(0.9) \mathrm{pmol}$ citrulline/mg/protein/min). There was no sig- 
Myocardial tissue from patients with dilated hearts of non-ischaemic origin (inflammatory) expressed inducible nitric oxide synthase (iNOS) with little or no constitutive nitric oxide synthase (cNOS). In contrast, myocardial tissue from patients with dilatation of ischaemic or valvar origin showed significant cNOS activity with little or no $i N O S$ activity. This distribution of enzyme activity was similar in myocardial tissue from patients with non-dilated hearts with ischaemic or valvar disease.

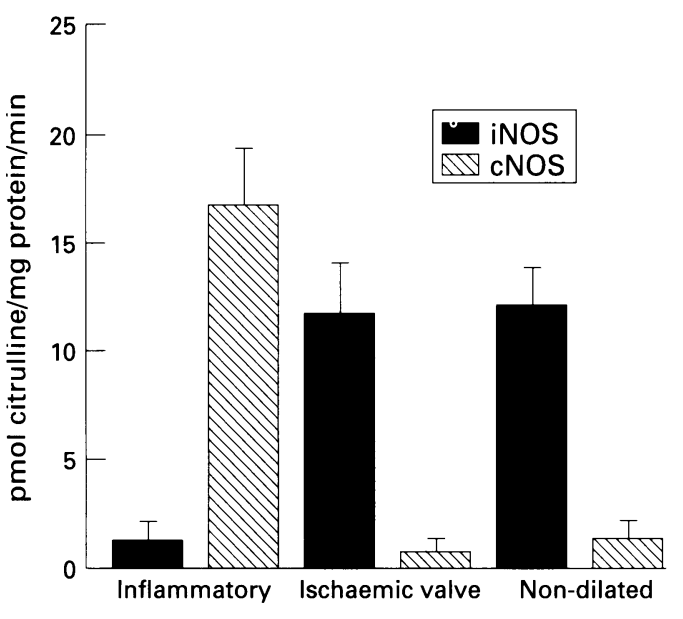

Characteristics, echocardiographic dimensions, and New York Heart Association classification of dyspnoea for each group of patients

\begin{tabular}{|c|c|c|c|}
\hline \multirow[b]{2}{*}{ Data } & \multicolumn{2}{|l|}{ Dilated } & \multirow[b]{2}{*}{$\begin{array}{l}\text { Non- } \\
\text { dilated }\end{array}$} \\
\hline & Inflammatory & $\begin{array}{l}\text { Ischaemic } \\
\text { or } \\
\text { valve disease }\end{array}$ & \\
\hline No $(M / F)$ & $14(9 / 5)$ & $9(6 / 3)$ & $8(6 / 2)$ \\
\hline Age & $48(12)$ & $42(14)$ & $52(16)$ \\
\hline \multicolumn{4}{|l|}{ Echo dimensions: } \\
\hline $\operatorname{LVEDD}(\mathrm{cm})$ & $7 \cdot 0(0 \cdot 6)$ & $6 \cdot 6(0 \cdot 5)$ & $4 \cdot 6(0 \cdot 5)$ \\
\hline $\operatorname{LVESD}(\mathrm{cm})$ & $6.0(0.5)$ & $5 \cdot 4(0 \cdot 6)$ & $3 \cdot 1(0 \cdot 8)$ \\
\hline \multicolumn{4}{|l|}{ NYHA: } \\
\hline I & 0 & 0 & 7 \\
\hline II & 2 & 4 & 1 \\
\hline III & 8 & 5 & 0 \\
\hline IV & 4 & 0 & 0 \\
\hline
\end{tabular}

Inflammatory dilated: includes patients with dilated cardiomyopathy (non-inflammatory and inflammatory) and peripartum cardiomyopathy; Non-dilated, includes patients
non-dilated hearts and ischaemic or valvar heart disease. non-dilated hearts and ischaemic or valvar heart disease. ventricular end systolic diameter.

nificant difference of iNOS activity between the three patient groups. In contrast, patients with dilatation of ischaemic or valvar origin showed significant cNOS $(11.7(2 \cdot 4) \mathrm{pmol}$ citrulline/mg protein $/ \mathrm{min}$ ) activity with little, if any, iNOS $(0.8(0.6) \mathrm{pmol}$ citrulline $/ \mathrm{mg}$ protein/min) activity. Myocardial tissue from patients with non-dilated heart disease had distributions of enzyme activities (cNOS $12 \cdot 1$ $(1 \cdot 8)$, iNOS $1.4(0 \cdot 8) \mathrm{pmol}$ citrulline $/ \mathrm{mg}$ protein $/ \mathrm{min}$ ) similar to those in patients with dilatation caused by ischaemic or valve disease (figure).

\section{CYTOKINE RESULTS}

Patients with histological evidence of inflammatory cardiomyopathy $(n=8)$ had detectable plasma concentrations of TNF $a(2.76$ $(1.62) \mathrm{ng} / \mathrm{ml})$. In all other patients with dilated or non-dilated hearts $(n=18)$ plasma concentrations of $\mathrm{TNF} a$ were below the detectable range.

\section{Discussion}

Several pathogenetic mechanisms lead to myocardial dilatation. Coronary artery occlusion leads to widespread myocyte necrosis, with subsequent scarring and thinning of the affected part of the ventricle, and left ventricular dilatation in chronic aortic valve regurgitation is caused by longstanding left ventricular volume overload. However, in several myocardial disorders that are associated with cardiac dilatation and impaired function the pathophysiological events leading to dilatation are less clear. These include dilated cardiomyopathy, acute myocarditis, peripartum cardiomyopathy, interleukin-induced cardiomyopathy, heart transplant rejection, AIDSrelated cardiomyopathy, and endotoxaemia. The histological appearances of these heart muscle disorders range from an intense inflammatory infiltrate with myocytolysis (acute myocarditis and severe cardiac transplant rejection) to essentially normal myocyte appearances, with a minor or relative lack of inflammatory cells (dilated cardiomyopathy). ${ }^{22}$ While the former could be explained (at least in part) by cytotoxicity mediated by $\mathrm{T}$ cells, the latter suggests that there must be other factors involved causing dilated impaired hearts.

Our results show that in patients with severely impaired cardiac function with a diagnosis of inflammatory and non-inflammatory dilated cardiomyopathy and peripartum cardiomyopathy there is significant expression of iNOS and low cNOS activity. In similarly dilated hearts where dilatation is of ischaemic or valvar origin expression of iNOS is very low and expression of $\mathrm{cNOS}$ is high. Furthermore, in non-dilated hearts where there is ischaemic or valvar disease most of the NO generation is the result of activity of the cNOS.

In addition, our results show that in patients with evidence of an inflammatory process within the myocardium, there is an increase in plasma TNF $\alpha$. Some cytokines, such as interleukin- $1 \beta$ (IL-1 $\beta$ ), interleukin-2 (IL-2), TNF $a$, and interferon- $\gamma$ (IFN- $\gamma$ ), are negatively inotropic in several in vitro cardiac preparations. ${ }^{23-25}$ The clinical use of some of these factors, such as IL-2 and IFN $\gamma$, for chemotherapy, is limited by the development of a cardiomyopathy. ${ }^{2627}$ Recent animal work has linked the negative inotropism of these cytokines to increased NO generation, and found that inhibition of NO biosynthesis improved the cytokine-induced depression of cardiac function. ${ }^{71718}$ Our observations have now provided a link between the release of TNF $a$, the expression of iNOS, and myocardial dilatation caused by myocardial inflammation.

The aetiology of DCM remains unknown. There is some evidence, by no means conclusive, that persistence of enteroviral activity has an aetiological link. ${ }^{28}$ Autoantibodies against normal and abnormal cardiac tissue have also been described. ${ }^{29-31}$ These two theories are not exclusive; because viral infection can lead to autoimmunity. ${ }^{32}$ Our results confirm our previous findings of the presence of the iNOS in heart tissue from patients with dilated cardiomyopathy. ${ }^{19}$ Whether this enzyme is present as a result of a viral and/or autoimmune trigger is a source of continued debate. It is interesting to speculate whether viral infection leads to induction of the iNOS in myocardial tissue as do some neurotropic viruses in the brain. ${ }^{33}$ 
Heart failure in association with pregnancy was first recognised in $1849,{ }^{34}$ and a primary heart muscle disease related to late pregnancy and the puerperium was described in $1870 .^{35}$ In our patients who had peripartum cardiomyopathy, there was histological evidence of an inflammatory process in hypertrophied dilated hearts, with thickening of the endocardium. Our results show that there is induction of the iNOS in right ventricular tissue of these patients, suggesting that NO generation by this enzyme may account for some of the impaired cardiac performance seen in this condition. It may be that NO is the postpartal factor present in peripartum cardiomyopathy, as suggested by Musser in $1938 .^{36}$

The NO synthase activities, whether $\mathrm{Ca}^{2+}$ dependent or independent, were similar. Under normal conditions, there is close physiological regulation of intracellular $\mathrm{Ca}^{2+}$ with each myocardial contraction cycle. However, when the $\mathrm{Ca}^{2+}$-independent iNOS is expressed, there is no regulatory mechanism to control NO generation; and therefore there will be a much longer net increase of $\mathrm{NO}$ over time, regardless of the level of intramyocyte $\mathrm{Ca}^{2+}$. Thus although under assay conditions the amounts of enzyme produced may be similar, the effect of iNOS expression in vivo may be quite different.

The generation of NO by iNOS in the myocardium may exert a negative inotropic effect by two mechanisms. One is by stimulation of the soluble guanylate cyclase with an increase in cyclic GMP, which is known to have a negative inotropic effect in several heart preparations. ${ }^{37}$ Interestingly, we have previously shown a rise in $\mathrm{Ca}^{2+}$-independent cyclic GMP in myocardium from patients with DCM. ${ }^{19}$ The other mechanism is a direct inhibitory effect of $\mathrm{NO}$ on $\mathrm{Fe}-\mathrm{S}$-containing enzymes of mitochondrial respiration, which would affect myocardial ATP production, ${ }^{38}$ as has been shown in cultured aortic smooth muscle cells. ${ }^{39}$

We found that in heart tissue where there was increased iNOS activity there was also a decrease in cNOS activity. There is growing evidence that these reciprocal interactions between iNOS and cNOS take place in other cells such as bovine aortic endothelial cells ${ }^{40}$ and human umbilical vein cells ${ }^{41}$ and may reflect a regulation of enzyme activities by cytokines, ${ }^{42}$ which increase the rate of cNOS mRNA degradation. ${ }^{41}$

Our studies did not determine the source of the NOS activity within the endomyocardial tissue. The presence of cNOS has been demonstrated in myocytes ${ }^{1}$ and endocardial cells ${ }^{4}$ in vitro and it is possible that neuronal NOS may contribute to this activity. Under the appropriate cytokine conditions cultured myocytes, ${ }^{1}$ endocardial cells, ${ }^{15}$ and white cells ${ }^{43}$ all have the capacity to express iNOS. Further immunological studies with in situ hybridisation will resolve this issue.

Animal studies have shown that the negative inotropism induced by IL- $1 \beta$ and TNF $\alpha$ could be ameliorated by the pharmacological inhibition of NO synthase activity. ${ }^{44}$ These results suggest that inhibition of NO synthase could be used to treat the negative inotropic effects associated with dilated hearts of inflammatory aetiology. However, the lack of selective inhibitors of iNOS seems to be an obstacle to the implementation of this therapeutic strategy. The NO synthase inhibitors available to date are not selective and also interfere with the activity of cNOS in myocardium, endocardium, endothelium, and platelets. This may lead to decreased blood flow, increased blood cell reactivity, and changes in myocardial contractility. However, development of selective inhibitors of the iNOS may provide a novel treatment for inflammatory heart disease.

JFM is a BHF Professor of Cardiovascular Science, AdeB is a BHF Intermediate Fellow. We thank Professor E Olsen for his histological expertise.

1 Schulz R, Nava E, Moncada S. Induction and potential biological relevance of a $\mathrm{Ca}^{2}$-independent nitric oxide synthase in the myocardium. Br $\mathcal{F}$ Pharmacol 1992;105: 575-80.

2 Palmer RMJ, Moncada S. A novel citrulline-forming enzyme implicated in the formation of nitric oxide by vascular endothelial cells. Biochem Biophys Res Commun 1989;158:348-52.

3 Moncada S, Palmer RMJ, Higgs EA. Nitric oxide physiology, pathophysiology and pharmacology. Pharmacol Rev 1991;43:109-42.

4 Schulz R, Smith JA, Lewis MJ, Moncada S. Nitric oxide synthesis in cultured endocardial cells of the pig. $\mathrm{Br} \mathcal{F}$ synthesis in cultured end

5 Balligand J-L, Kelly RA, Marsden PA, Smith TW, Michel $\mathrm{T}$. Control of cardiac muscle cell function by an endogenous nitric oxide signalling system. Proc Natl Acad Sci USA 1993;90:347-51.

6 Brady AJB, Warren JB, Poole-Wilson PA, Williams TJ, Harding SE. Nitric oxide attenuates cardiac myocyte contraction. Am F Physiol 1993;265:H176-82.

7 Finkel MS, Oddis CV, Jacob TD, Watkins SC, Hattler BG, Simmons RL. Negative inotropic effects of cytokines on the heart mediated by nitric oxide. Science 1992;257:387-9.

8 Shah AM, Lewis MJ. Modulation of myocardial contraction by endocardial and coronary vascular endothelium tion by endocardial and coronary vas
Trends Cardiov Med 1993;3:98-103.

9 Geller DA, Lowenstein CJ, Shapiro RA, Nussler AK DiSilvio M, Wang SC, et al. Molecular cloning and expression of inducible nitric oxide synthase from human hepatocytes. Proc Natl Acad Sci USA 1993;90. 3491-5.

10 Charles IG, Palmer RMJ, Hickery MS, Bayliss MT Chubb AP, Hall VS, et al. Cloning, characterisation and expression of a cDNA encoding an inducible nitric oxide synthase from the human chondrocyte. Proc Natl Acad Sci USA 1993;90:11419-23.

11 Rees DD, Cellek S, Palmer RMJ, Moncada S. Dexamethasone prevents the induction by endotoxin of a nitric oxide synthase and the unwanted effects on vascular tone. An insight into endotoxin shock. Biochem Biophys Res Commun 1990;173:541-7.

12 Radomski MW, Palmer RMJ, Moncada S. Glucocorticoids inhibit the expression of an inducible, but not corticoids inhibit the expression of an inducible, but not the constitutive nitric oxide synthase in vascular
endothelial cells. Proc Natl Acad Sci USA 1990;87: 10043-7.

13 Petros A, Bennett D, Vallance P. Effect of nitric oxide synthase inhibitors on hypotension in patients with septic shock. Lancet 1991;338:1557-8.

14 Moncada S. The 1991 Ulf von Euler Lecture. The L arginine nitric oxide pathway. Acta Physiol Scand 1992, 145:201-27.

15 Smith JA, Radomski MW, Schulz R, Moncada S, Lewis MJ. Porcine ventricular endocardial cells in culture express the inducible form of nitric oxide synthase. $\mathrm{Br} F$ Pharmacol 1993;108:1107-10.

16 Brady AJB, Poole-Wilson PA, Harding SE, Warren JB Nitric oxide production within cardiac myocytes reduces their contractility in endotoxaemia. Am f Physiol 1992; 263: H1963-6.

17 Evans HG, Lewis MJ, Shah AM. Interleukin- $1 \beta$ modulates myocardial contraction via dexamethasone-sensitive production of nitric oxide. Cardiovasc Res 1993;27:1486-90. 18 Balligand J-L, Ungureanu D, Kelly RA, Pimental D,
Michel T, Smith TW. Abnormal contractile function due to induction of nitric oxide synthesis in rat cardiac myocytes follows exposure to activated macrophageconditioned medium. 7 Clin Invest 1993;27:1486-90. 
19 de Belder AJ, Radomski MW, Why HJF, Richardson PJ, Bucknall CA, Salas E, Martin JF, Moncada S. Nitric oxide synthase activities in human myocardium. Lancet 1993;341:84-5.

20 Demakis JG, Rahimtoola SH. Peripartum cardiomyopathy. Circulation 1971;44:964-8.

21 Radomski MW, Vallance P, Whitley G, Foxwell N, Moncada S Platelet adhesion to human vascular endothelium is modulated by constitutive and cytokine induced nitric oxide. Cardiovasc Res 1993;27:1380-3.

22 Olsen EGJ. Pathology of cardiomyopathies. A critica analysis. Am Heart f 1979;98:385-92.

23 Hosenpud JD, Campbell SM, Mendelson DJ. Interleukin1 -induced myocardial depression in isolated beating heart preparations. $\mathcal{F}$ Heart Transpl 1989;8:460-4.

24 Sobotka PA, McMannis J, Fisher RI, Stein DG, Thomas $\mathrm{JX} \mathrm{Jr}$. Effects of interleukin-2 on cardiac function in the isolated rat heart. $\mathcal{F}$ Clin Invest 1990;86:845-50.

25 Hollenberg SM, Cunnion RE, Lawrence M, Kelly $\pi$ Parillo JE. Tumour necrosis factor depresses myocardia cell function. Results using an in vitro assay of myocyte performance. Clin Res 1989;37:528.

26 Nora R, Abrams JS, Tait NS, Hiponia DJ, Silverman HJ. Myocardial toxic effects during interleukin-2 treatment. 7 Natl Cancer Int 1989;81:59-63.

27 Sonnenblick $M$, Rosen A. Cardiotoxicity of interferon-a review of 44 cases. Chest 1991;99:557-61.

28 Tracy S, Wiegand V, McManus B, Gauntt C, Pallansch Mracy S, Wiegand V, McManus B, Gauntt C, Pallansch $\mathrm{M}$, Beck M, et al. Molecular approach to enteroviral
diagnosis in idiopathic cardiomyopathy and myocarditis. diagnosis in idiopathic cardiomyopa
7 Am Coll Cardiol 1990;15:1688-94.

29 Limas CJ, Goldenberg IF, Limas C. Autoantibodies against $\beta$-adrenoreceptors in human idiopathic dilated cardiomyopathy. Circ Res 1989;64:97-103.

30 Schultheiss H-P, Bolte H-D. Immunological analysis of autoantibodies against the adenine nucleotide translocator in dilated cardiomyopathy. $7 \mathrm{Mol}$ Cell Cardiol 1985;17:603-17.

31 Caforio AL, Grazzini M, Mann JM, Keeling PJ, Bottazzo GF, McKenna WJ, et al. The identification of alpha- and beta-cardiac myosin heavy chain isoforms as major autoantigens in dilated cardiomyopathy. Circulation 1992;85: antigens $1734-42$.

32 Rose NR, Neu N, Neuman A, Herskowitz A. Myocarditis: a postinfectious autoimmune disease. In: Schultheis $\mathrm{HP}$, ed. New concepts of viral heart disease. Berlin Springer-Verlag 1988:139-47.
33 Koprowski H, Zheng YM, Heber-Katz E, Fraser N, Rorke L, Fu ZF, et al. In vivo expression of inducible nitric oxide synthase in experimentally induced neurological disease. Proc Natl Acad Sci USA 1993;90 3024-7.

34 Ritchie C. Clinical contribution to the pathology, diagnosis and treatment of certain chronic diseases of the heart. Edinburgh Med Surg f 1849;2:333.

35 Virchow R. Sitzung der Berliner Geburtschueflicher Gesellschaft. 1870.

36 Musser JH, Sodeman WA, Turner RH. Heart failure or acute nephritis with onset about 3 weeks after delivery.

37 Lohmann SM, Fischmeister R, Walter V. Signal transduction by cGMP in the heart. Basic Res Cardiol 1991 86: 503-14.

38 Drapier J-C, Hibbs JB Jnr. Differentiation of murine macrophages to express nonspecific cytotoxicity for tumor cells results in L-arginine-dependent inhibition of mitochondrial iron-sulfur enzymes in the macrophage effector cells. $f$ Immunol 1988;140: 2829-38.

39 Geng Y, Hansson GK, Holm E. Interferon- $\gamma$ and tumour necrosis factor synergize to induce nitric oxide production and inhibit mitochondrial respiration in production and inhibit mitochondrial respiration in
vascular smooth muscle cells. Circ Res 1992;71: 1268-76.

40 Lamas S, Michel T, Brenner BM, Marsden PA. Nitric oxide synthesis in endothelial cells: evidence for a pathway inducible by TNF-alpha. Am f Physiol 1991: C634-C641.

41 Yoshizumi M, Perrella MA, Burnett JC, Lee M-E. Tumor necrosis factor downregulates an endothelial nitric oxide synthase mRNA by shortening its half-life. Circ Res 1993;73:205-9.

42 Forstermann U, Kuk JE, Nakane $M$, Pollock JS. The expression of endothelial nitric oxide synthase is downregulated by tumor necrosis factor $a$ (TNF $a$ ). Naunyn Schmeidebergs Arch Pharmacol 1993;347:R61.

43 Paul-Eugene N, Kolb J-P, Damais C, Dugas B Heterogenous nitrite production by IL-4-stimulated heterogenous nitrite production by IL-4-stimulated human monocytes and peripher

44 Schulz R, Panas DL, Catena R, Moncada S, Olley PM, Lopaschuk GD. The role of nitric oxide in cardiac depression induced by interleukin- $1 \beta$ and tumour necrosis factor-a. Br $\mathcal{F}$ Pharmacol 1995;114:27-34. 